\title{
Self-feeding behaviour and personality traits in tilapia: a comparative study between Oreochromis niloticus and Sarotherodon melanotheron
}

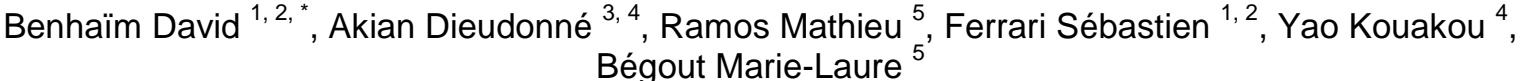

${ }^{1}$ Laboratoire universitaire des sciences appliquées de Cherbourg, Normandie Univ., UNICAEN, LUSAC, 50100 Cherbourg, France

${ }^{2}$ Conservatoire National des Arts et Métiers. Intechmer, 50100 Cherbourg, France

3 INP-HB, Département FOREN, Yamoussoukro, Cote d'Ivoire

${ }_{5}^{4}$ UNA, UFR-SN, Laboratoire de Biologie et Cytologies Animales, Abidjan, Cote d'Ivoire

${ }^{5}$ Ifremer, Laboratoire Ressources Halieutiques, place Gaby Coll, 17137 L'Houmeau, France

* Corresponding author : David Benhaïm, email address : david.benhaimmea1@gmail.com

\begin{abstract}
:
Hybridization aims at combining valuable traits from two species into a single group. Nile tilapia Oreochromis niloticus (NT) and Black-chinned tilapia Sarotherodon melanotheron (BCT) are respectively characterized by fast growth and water salinity tolerance which attract the breeders who could take advantage of both species. The first step is to characterize both species behavior in different contexts. The aim of this study was to compare the self-feeding behaviour between NT and BCT with a design allowing to reveal individual and group feed demand behaviour and then to identify the individual specialization that builds around the device and the food dispenser. The second objective was to estimate the links between the individual specialization and personality traits. To this aim, we recorded feed demand behaviour of both species using a computerized self-feeding device (two tanks for each species containing 20 PIT-tagged individuals with a male-female ratio of about $47 \%$ ). Personality traits of all individuals were subsequently characterized with an open field test (OFT). The links between feeddemand and personality were then analyzed. Growth performances were not significantly different between NT and BCT but there was a strong tank effect. The individual specialization was similar in NT and BCT and similar to that previously observed in sea bass i.e. 1-3 individuals responsible for most of the feed demand activity in the tanks. Most NT individuals stayed in the shelter during the open field test while most of BCT individuals moved out of it. Overall, NT were shyer than BCT or the OFT was not adapted to NT. Linking the results of the self-feeding experiment and OFT in BCT, we found a strong positive correlation between the triggering activity and females' shyness. Fish that spent more time inside than outside the shelter and which latency to emerge from shelter was longer, were characterized by a higher triggering activity (high-triggering fish). This study confirms the NT ability to use self-feeder devices and provides the first insight into the same ability in BCT and demonstrates links with personality traits. These results have a potential interest for the success of BCT and NT hybridization.
\end{abstract}




\section{Highlights}

- We compared the self-feeding behaviour between Nile and Black-chinned tilapia. $>$ We estimated the links between the social structure and personality traits. The social structure was similar between NT and BCT We found a strong positive correlation between the triggering activity and female shyness.

Keywords : boldness, personality, self-feeder, individual specialization, social structure 


\section{Introduction}

Feed management is crucial for the economic performance of a fish farm. It involves avoiding either underfeeding, which inhibits growth and promotes competition (McCarthy et al., 1992), or overfeeding which increases food wastage (Thorpe and Cho, 1995) and feed conversion ratios (Talbot, 1993). Feeding behavior is a complex and flexible behavior that encompasses several behavioral responses associated with eating, including modes of feeding and feeding habits, mechanisms of food detection, frequency of feeding and food preferences (Volkoff and Peter, 2006).

Self-feeder devices have been developed to avoid both under- and over feeding with the fish obtaining food according to their nutritional needs (Covès et al., 2006). These devices have been widely used for studying feeding behaviour and especially feed palatability and nutrient selection (Boujard and Le Gouvello, 1997). When coupled with a computer and a PIT tag detection antenna, self-feeder devices give the possibility to reveal individual and group feed demand behavior. They allowed the assessment of numerous variables such as apparent group feed demand and consumption (when uneaten food is counted); feeding activity and feeding 
rhythms in Arctic char Salvelinus alpinus and European seabass Dicentrarchus labrax (Boujard et al., 1996; Rubio et al., 2004; Covès et al., 2006); circadian rhythms in rainbow trout Oncorhynchus mykiss (Alanärä, 1992; Boujard and Leatherland, 1992; Alanärä, 1996), and feed preferences in seabass (Paspatis et al., 2002). Most studies report the existence of individual specialization, also and hereafter called 'social structure' built around the device and the food dispenser. For example, social hierarchies have been observed in salmonids such as rainbow trout (Alanärä, 1996), or Arctic char (Brännäs and Alanärä, 1993), with dominant fish taking position near the feeder and the dispenser. These authors identified three fish categories (dominants, sub-dominants and subordinates): Dominant fish had the highest actuation level, followed by sub-dominants and then subordinates, resulting in higher specific growth rates for dominant fish. In European seabass and European cod (Gadus morhua), an intriguing individual specialization exists with three triggering categories coexisting: high-triggering (HT), lowtriggering (LT) and zero-triggering (ZT) fish (Covès et al., 2006; Di-Poï et al., 2007; Millot et al., 2008; Millot and Bégout, 2009; Millot et al., 2014). In small populations composed of 50100 fish, whatever the experimental conditions, the same pattern is always observed: HT fish are very few with only one or two animals being responsible for most of the triggering activity under a reward regime of 1 or 2 pellets per individual given after each actuation (Covès et al., 2006). On the other hand, the ZT status would be attributed to fish that never actuate the device while the rest of the population was composed of individuals that seldom actuated the trigger (LT) (Covès et al., 2006; Millot et al., 2008). This social structure is better and better understood in light of recent studies showing that the fish triggering activity is linked to personality traits (Benhaïm et al., 2012; Ferrari et al., 2014).

Animal personality can be defined as a correlated set of individual behavioural and physiological characteristics that are consistent over time and across situations (Wilson, 1994; Koolhaas et al., 1999; Sih et al., 2004). One of the main aspects of personality is the boldnessshyness continuum. Bold fish take more risks and explore their environment faster (less cautiously) when exposed to novelty (Øverli et al., 2006; MacKenzie, 2009). In contrast, shy individuals tend to be risk averse and are generally neophobic (Verbeek et al., 1994; Wilson, 1994), show a higher behavioural flexibility (Bolhuis, 2004) and are more responsive to their environment (Verbeek et al., 1994). Intermediate fish are in the middle of these two extremes. Among numerous behavioural tests assessing boldness, the open field test is widely used (Budaev, 1999a; Yoshida, 2005; Ferrari et al., 2014; Benhaïm et al., 2016). 
Behind carps, tilapia is the second most farmed fish in the world. Even if the species is collectively called "tilapia", it includes in reality several genuses among which we find the black-chinned tilapia Sarotherodon melanotheron (BCT) and the Nile tilapia Oreochromis niloticus (NT), two species differentiated by their mode of parental care (oral incubation) (Trewaras, 1983). Today, 90\% of these farmed fish are NT which grows particularly well but has a very low tolerance to salinity. Conversely, BCT has naturally low growth capacities but tolerates high salinity level (Whitfield and Blaber, 1979; Stickney, 1986). Fast growth of the first one and water salinity tolerance of the second species attract the breeders who could take advantages of both species characteristics by producing hybrids. This has been frequently attempted (Hopkins et al., 1989; Suresh and Lin, 1992) but seldom achieved although hybrids were produced in brackish waters recently (Amon et al., 2013). There are still concerns including interspecific aggressive behavior requiring further research on breeding conditions allowing hybridization (Akian et al., in preparation).

NT fish has also been used in studies addressing some themes of neuroscience and behaviour, such as stress (Volpato and Barreto, 2001; Barreto and Volpato, 2004; Moreira and Volpato, 2004); anxiety, emotionality and/or defence (Ide and Hoffmann, 2002; Barreto et al., 2003); drugs affecting feeding behaviour (Delicio and Vicentini-Paulino, 1993) and personality traits (Martins et al., 2011a; Martins et al., 2011b). Despite a large number of reports on nutrition (Martins et al., 2011b; Ng and Wang, 2011; Teoh et al., 2011; Trung et al., 2011) very little characterization has, however, been done on self-feeding behaviour of NT and none on BCT. Previous studies showed that NT can use self-feeders efficiently to finely adjust food intake according to diet composition and contributions of nutrients from the diets (Fortes-Silva et al., 2010; Fortes-Silva and Sanchez-Vazquez, 2012) but the individual specialization based on the triggering activity and its link with personality traits has not been investigated so far.

The first aim of this study was to compare the self-feeding behaviour between NT and BCT with a design allowing to reveal individual and group feed demand behaviour and then to identify the social structure that builds around the device and the food dispenser. The second objective was to estimate the links between the individual specialization on the self-feeder and personality traits (boldness / shyness, exploration, activity).

\section{Materials and methods}

\subsection{Experimental animals and housing conditions}


Fish from both species (Oreochromis niloticus and Sarotherodon melanotheron) were hatched and reared at the experimental station of CIRAD (Montpellier, France). They were the first generation obtained in a recirculating system. NT were produced by the crossing of parents originating from the Bouaké strain in Ivory Coast while BCT were produced by the crossing of parents originating from the Ebrié lagune strain in Ivory Coast. NT growth is so much faster than that of BCT that we made the choice to compare them at similar size but not the same age in order to make the behavioural observations more relevant. A sample of $45 \mathrm{NT}$ and $39 \mathrm{BCT}$ was then transported at 1079 days post hatching (dph) and 1667 dph respectively to the Fish Ecophysiology Platform of La Rochelle (PEP, http://wwz.ifremer.fr/pep, France) and distributed in four $400 \mathrm{~L}$ tanks (T1 to T4) located in a dedicated room : T1 (BCT, 11 females and 8 males), T2 (BCT, 11 females and 9 males), T3 (NT, 13 females, 10 males), T4 (NT, 13 females, 9 males).

At 1771 and $1183 \mathrm{dph}, \mathrm{NT}$ and BCT weighing $221.9 \pm 97.9 \mathrm{~g}, 175.9 \pm 22.0 \mathrm{~g}$ respectively were tagged with $12 \mathrm{~mm}$ conventional PIT tag to monitor each fish individually using a self-feeder equipped with PIT tag detection antenna.

The four tanks were supplied with filtered domestic water (Atlas cartridge) that removed organic matter and chlorine and further treated by a filter (flow rate of $300 \mathrm{~L} \mathrm{~h}^{-1}$ in each tank, and $20 \%$ water renewal per day). Tanks were surrounded by an opaque black curtain to avoid any disturbance of the fish. Nets were used to prevent the fish from jumping out of the tanks. A white light (LED, PAR 38, $120 \mathrm{~W}$ ) was suspended above each tank. Light regime was 12:12 LD (light onset at 09:00 U.T. + 1). The physico-chemical properties of the water were monitored daily to guarantee optimum conditions. Water temperature was maintained at $24.8 \pm$ $0.4^{\circ} \mathrm{C}, \mathrm{O}_{2}$ saturation at $72.7 \pm 12.9 \%$, conductivity at $567.9 \pm 57.2 \mu \mathrm{S} \mathrm{cm}^{-1}, \mathrm{pH}$ at $6.59 \pm 0.51$. Ammonia, nitrite and nitrate concentrations were $0.26 \pm 0.21,0.58 \pm 0.16$ and $7.00 \pm 5.84 \mathrm{mg}$ $\mathrm{L}^{-1}$, respectively. Fish were fed with commercial food (EFICO YM 868, 3 mm, BIOMAR ${ }$, France).

\subsection{Feed demand behavior and self-feeder apparatus}

The device to operate the feeder comprised a screened type sensor (a metal rod protected in a PVC cylinder surrounded by the tag detection antenna (Covès et al., 2006) and a control box linked to a computer (Imetronic, Pessac, France). After each actuation, fish were rewarded with 
pellets (at least one per fish) and feed dispensers were regulated to always distribute the same quantity of food, which corresponded to a mean of $1.17 \pm 0.04 \mathrm{~g}$. The reward level was a compromise between minimizing wastage, and optimizing feed allocation to the group. Such a set up allowed us to monitor two variables of interest on a daily basis: the individual feed demand behavior and the apparent feed consumption of the group (i.e. one group per tank). The apparent feed consumption of the group was calculated from the food quantity dispensed minus the waste collected in the sediment trap and counted. Triggering activity recordings were done continuously except before and during fish biometry sessions (triggers were inactivated and there were no recordings for $48 \mathrm{~h}$ at each biometry session). Feed demand behaviour was followed over 66 days from 1776 to $1842 \mathrm{dph}$ for NT and from 1188 to $1254 \mathrm{dph}$ for BCT.

\subsection{Evaluation of biological performances and feed demand characteristics}

The growth of all fish was followed every three weeks from 1771 to $1842 \mathrm{dph}$ for NT and 1183 to $1254 \mathrm{dph}$ for BCT. The variables chosen to evaluate biological performances within periods (i.e. in between biometric measurements) were the following:

- Body weight (BW in g), Standard body length (BL in cm), Specific growth rate: SGR (\% body weight per day $)=100(\operatorname{Ln~BWf}-\mathrm{Ln} \mathrm{BWi}) / \mathrm{t}$, with BWf and BWi being the final and initial body weight $(\mathrm{g})$, respectively, and $\mathrm{t}$ the total number of days, Fulton index $\left(\mathrm{K}=100 \times \mathrm{BW} \times\left(\mathrm{BL}^{3}\right)^{-1}\right)$ were measured on each fish.

- Feed demand (FD in $\mathrm{g} \mathrm{kg}^{-1}$ of fish biomass), Food wastage (FW in $\mathrm{g}$ ), and Feed Conversion Ratio $(\mathrm{FCR}=\mathrm{FD} /$ biomass gain) were measured at the tank level.

- Daily feeding rhythms (measured at the tank level also) were calculated by taking into account the feeding demand per hour.

\subsection{Social structure based on triggering activity}

Individuals were classified into 3 categories according to their proportional contribution to total number of trigger actuations within a group (triggering activity) over the 66 days of monitoring: high-triggering HT (>15\% actuations), low-triggering LT (5-15\%), and zero-triggering ZT (0$5 \%$ ) individuals (based on Covès et al., 2006).

\subsection{Characterization of personality traits}


Observations were made in a dedicated room. All experiments were video recorded at 25 frames per second (Ethovision XT recording, Noldus, the Netherlands; camera Ikegami CD48E; 2.8 $12 \mathrm{~mm}$ Computar ${ }^{\circledR}$ lens equipped with an IR filter positioned at $180 \mathrm{~cm}$ above the water surface). An infrared casing $(1 \times 1 \mathrm{~m}$, Noldus, The Netherlands $)$ was placed under the apparatus used in this experiment to enable the recording of videos at low light intensity and to improve video analysis. Two LED (PAR 38, $120 \mathrm{~W}$ ) were horizontally placed on walls located on the left and right sides of the infrared casing. They were located $150 \mathrm{~cm}$ above the infrared casing and provided an indirect and homogenous lighting on the apparatus.

An open field test (OFT) was performed on all individuals at the end of the self-feeding experiment. The open field $(110 \mathrm{~cm} * 110 \mathrm{~cm}$ with a water height of $17 \mathrm{~cm}$, Figure 1) contained a shelter placed in one corner (opaque PVC box $50 \mathrm{~cm} * 50 \mathrm{~cm} * 23 \mathrm{~cm}$ closed by a vertically sliding opaque trapdoor) and was divided into four virtual zones using the software Ethovision XT: Shelter, Pre-shelter, Border and Center. The center zone was considered a risky area because thigmotaxis (staying close to the walls of an arena) is a common measure indicative of a high degree of shyness in such an apparatus (Maximino, 2010; Dahlbom, 2011). Selected fish were individually placed in the shelter. After a $5 \mathrm{~min}$ acclimatization period, the door was gently opened. If the individual did not leave the shelter within 20 min following the acclimatization time, the experiment was stopped and a latency of $1200 \mathrm{~s}$ was attributed. Variables of interest were extracted with Ethovision XT and were as follows:

- The latency of each individual to emerge from the shelter (Lat in s), the proportion of time $(\%)$ respectively spent in the shelter (Shelter), the center zone (Center), the border zone (Border) and the pre-shelter zone (Pre-Shelter).

- The mean distance from the shelter (DtoShelter in $\mathrm{cm}$ ) and the number of returns to the shelter (FreqShelter).

- The distance travelled by each fish in the device (Dtot in $\mathrm{cm}$ ), the absolute angular velocity of the fish expressed in degrees per second (Vang in ${ }^{\circ} \mathrm{s}^{-1}$ ), and its mean velocity expressed in body length per second (Vel in BL s${ }^{-1}$ ).

\subsection{Statistical analyses}

\section{Self-feeding experiment}

All variables were compared using parametric analysis of variances (ANOVA) after verification of distribution normality, and homoscedasticity (Dagnélie, 1975). When data did 
not fulfil these requirements, non-parametric Kruskall-Wallis tests were used. Significant ANOVA were followed by a posthoc multiple comparison test (Newman-Keuls) and significant Kruskall-Wallis tests by rank-based multiple comparisons (Zar, 1984). All statistical analyses were conducted using Statistica 8 (Statsoft, USA) with the significance threshold $\mathrm{p}<$ 0.05 for all tests.

To assess for growth performances differences between both species, BW, BL and K were compared using 4-way ANOVA with Date (four dates corresponding to 4 biometry measurement dates), Species (two species), sex as fixed factors and Tank as a random factor nested to Species. SGR was compared using 4-way ANOVA with Date (three periods corresponding to intervals between the 4 biometry measurement dates), Species (two species), Sex as fixed factors and Tank as a random factor nested to Species.

FD, FW and FCR were compared using a three-way ANOVA with Species and Date (three dates) as fixed factors and Tank as a random factor nested to Species.

Feeding rhythms were analyzed within each tank looking at the FD per hour and using a Kruskall-Wallis test with Time as a fixed factor.

SGR of the 3 fish triggering categories within NT and BCT were compared using a 2-way ANOVA with Triggering category (HT, LT and ZT) as fixed factors and Tank as a random factor. A $\chi 2$-test was used within NT and BCT to compare the sex ratios between Triggering categories.

\section{Open field test experiment}

All the variables measured in the OFT were compared between and within both species using Kruskall-Wallis tests.

All the variables measured in OFT were collapsed within species into first principal component scores using Principal Components Analysis (PCA). A correlation matrix was used to verify multicollinearity, i.e., to identify variables that did not correlate with any other variable, or correlate very highly $(r=0.9)$ with one or more variables. Those latter variables were removed from downstream analyses. The remaining selected variables used for the PCA were: Shelter, Center, Border, Pre-Shelter and Lat. Each individual fish was then affected a PC1 score later used in cross-context analysis. For cross-context analysis (between tests), we analyzed, for each 
sex separately, the correlation between individual total number of feed demand recorded during the self-feeding experiment and PC1 individual scores from OFT using Spearman's correlation coefficient.

\section{Results}

\section{Growth performances and social structure under self-feeding conditions}

During the experiment, only two individuals coming from T4 (NT) died after jumping out from the tank despite the net protection. BW and K (Figure 2, A and D) did not differ significantly between species but there were in both cases a Tank(Species) significant effect $\left(\mathrm{F}_{(2,244)}=17.6\right.$, $p<0.001$ and $\mathrm{F}_{(2,244)}=13.6, p<0.001$, respectively) with NT in T4 being significantly higher compared to all other conditions $(P<0.001$ in all cases $)$ and a Date effect $\left(\mathrm{F}_{(3,244)}=3.3, p=\right.$ 0.02 and $\mathrm{F}_{(3,244)}=4.5, p=0.004$, respectively) with Date 1 being significantly lower than other dates $(P=0.04$ in both cases) for BW and Date 3 being significantly higher than all other dates ( $P=0.04$ and $P=0.004$ respectively) for $\mathrm{K}$.

BL (Figure 2, B) was significantly higher in NT $\left(\mathrm{F}_{(1,244)}=28.3, p<0.001\right)$ and there was a $\operatorname{Tank}\left(\right.$ Species) significant effect $\left(\mathrm{F}_{(2,244)}=11.1, p<0.001\right)$ with NT in T4 being significantly higher compared to all other conditions $(P<0.001$ in all cases $)$ and a Date effect $\left(\mathrm{F}_{(3,244)}=2.9\right.$, $p=0.03)$ with Date 1 being significantly lower than all other dates $(P=0.04)$.

SGR (Figure 2, C) did not differ significantly between species but there was a Tank (Species) significant effect $\left(\mathrm{F}_{(2,241)}=35.3, p<0.001\right)$ with NT in T4 being significantly higher compared to all other conditions $(P<0.001$ in all cases $)$ and a Date effect $\left(\mathrm{F}_{(2,241)}=19.4, p<0.001\right)$ with Date 1 being significantly higher than Date $2(P=0.01)$ and Date $3(P<0.01)$ and Date 2 significantly higher than Date $3(P<0.01)$.

FCR (Figure 2, E) did not differ significantly between species but there was a Tank(Species) significant effect $\left(\mathrm{F}_{(2,259)}=23.3, p<0.001\right)$ with BCT in T2 being significantly higher compared to all other conditions $(P<0.001$ in all cases $)$ and a Date effect $\left(\mathrm{F}_{(2,259)}=6.5, p=\right.$ $0.002)$ with Date 3 being significantly lower than Date $1(P=0.003)$ and Date $2(P<0.004)$. 
FD did not differ between species but there were a Tank(Species) significant effect $\left(\mathrm{F}_{(2,260)}=\right.$ 22.3, $p<0.001)$ with NT in T4 being significantly higher compared to all other conditions $(P$ $<0.001$ in all cases $)$ and a Date effect $\left(\mathrm{F}_{(2,260)}=7.6, p<0.001\right)$ with Date 1 being significantly higher than all other dates $(P<0.01$ in all cases).

No significant difference was recorded for FW that was very low in all tanks $(0.42 \pm 3.8 \mathrm{~g}$ per day).

There were significant Time effects for FD in T1, 2,3 and $4\left(\mathrm{H}_{(23,318)}=51.1, p<0.001 ; \mathrm{H}_{(23}\right.$, $360)=44.9, p=0.004 ; \mathrm{H}_{(23,925)}=78.9, p<0.001 ; \mathrm{H}_{(23,296)}=71.5, p<0.001$ respectively, Figure 3). In T1, FD at $21 \mathrm{~h}$ was significantly lower than FD at 9 to $13 \mathrm{~h}, 16,19$ and $20 \mathrm{~h}(P<0.01$ in all cases). In T2 no further rank-based multiple comparisons was significant. In T3, FD at 19h was significantly higher than FD at 3, 7, 10, 11 and $14(P<0.01$ in all cases $)$ and FD at 20h was significantly higher than FD at 3, 7, 8, 10 to 12 and 14 ( $P<0.01$ in all cases). In T4, FD at $17 \mathrm{~h}$ was significantly higher than FD at $9 \mathrm{~h}(P=0.04)$.

No sex difference was recorded for any variables.

The social structure was similar between NT and BCT. There were between 1 and 3 individuals responsible for $33-94 \%$ and between 1 to 6 individuals responsible for $5-15 \%$ of the total FD activity according to the tank (Figure 4). The rest of the population i.e. between 12 to 17 individuals were responsible for $0-5 \%$ of the total FD activity according to the tank.

In both species, SGR was not significantly different between triggering categories.

The differences in sex ratio between the triggering categories were significant in BCT and NT $\left(\chi^{2}=2.16\right.$, d.f. $=2, p<0.05$ and $\chi^{2}=0.103$, d.f. $=2, p<0.05$ respectively $)$. There were $64 \%$ of females in HT NT, $50 \%$ of females in other categories (LT and ZT). There were $75 \%$ of females in HT BCT, $80 \%$ of females in LT, $50 \%$ of females in ZT.

\section{Open field experiment}

Only 8 out of 42 NT moved out of the shelter while 30 out of 37 BCT moved out of the shelter. Including those fish with a latency of $1200 \mathrm{~s}$, the mean latency to emerge from the Shelter was significantly longer for NT than for BCT $(1025.9 \pm 383.8 \mathrm{~s}$ and $519.8 \pm 435.2 \mathrm{~s}$ respectively, $\left.\mathrm{H}_{(1,73)}=20.1, p<0.0001\right)$. 
FreqShelter and Dtot were significantly higher in BCT than in NT $(3.5 \pm 4.8$ and $0.5 \pm 1.4$, $\mathrm{H}_{(1,73)}=10.9, p<0.001 ; 1729 \pm 1773.9 \mathrm{~cm}$ and $116.0 \pm 252.2 \mathrm{~cm}, \mathrm{H}_{(1,73)}=28.1, p<0.0001$ respectively). NT spent more time in Shelter than BCT (Figure 5). BCT spent more time in all other zones than NT. Within species, the proportion of time spent in the apparatus significantly differed between zones (Kruskal-Wallis test: $\mathrm{H}_{(3,148)}=48.4, p<0.0001$ in BCT and $\mathrm{H}_{(3,144)}=$ 101.6, $p<0.0001$ in NT) with fish spending more time in the Shelter zone than in all other zones $(p<0.0001$ in all cases $)$.

\section{Links between feed-demand and open field test results}

The links between feed demand and open-field test results was examined only in BCT because the majority of the NT individuals did not move out of the shelter.

The first component (PC1) explained $68 \%$ of the variation in the data (loadings: Shelter $=0.98$, Border $=-0.87$, Center $=-0.54$, Pre-Shelter $=-0.72$, Lat $=0.93)$. PC1 was therefore related to two extremes: the negative pole to high values of Border (contribution to the first component was 0.22 and the correlation was 0.76 ), the positive one to high values of Shelter and Lat (contributions to the first component were 0.28 and 0.25 and the correlations were 0.96 and 0.86 respectively). PC1 represented therefore a gradient from shy (high values of Shelter and Lat) to bold individuals (high values of Border).

In females, the feeding demand was positively correlated with PC1 individual scores $\left(\mathrm{r}_{\mathrm{s}}=0.49\right.$, $\mathrm{N}=21, \mathrm{p}=0.02$, Figure 6) i.e. high-triggering female fish were shyer than low-triggering and zero-triggering fish. In males, this correlation was found non significant $\left(\mathrm{r}_{\mathrm{s}}=0.24, \mathrm{~N}=16, \mathrm{p}=\right.$ 0.36 , Figure 6).

\section{Discussion}

Under self-feeding conditions growth performances were not significantly different between NT and BCT. Both species adapted to the self-feeding system without wasting feed and showing similar social structures. Large behavioural differences occurred between species in the open-field test i.e. NT was shyer than BCT. At last, we found a strong positive correlation between the triggering activity and shyness in BCT females. 


\section{Growth performances and social structure under self-feeding conditions}

Growth performances were not significantly different between NT and BCT. The most rapid growth was observed in one of the two NT tanks with SGR between 1.6 and $0.5 \%$ from the beginning to the end of the period. This is still lower than what was found in a previous study on NT under similar conditions (Toguyeni et al., 1997), but in our study the fish were much older and SGR is known to decrease with age (Hoare and Randall, 1979). In all other tanks, growth parameters such as body weight and body length remained stable from the beginning to the end of the experiment. These parameters were sometimes observed to decrease between dates and this was associated to a decrease in the feed demand co-occurring at the time mouth breeding was observed in both species. In one BCT tank, the low growth observed was associated with a low and highly variable feed efficiency. Further research is needed to understand these results that could be explained by social interactions and/or energy allocation differences in these tanks.

Tank effect has already been shown in previous studies on other species such as the European sea bass and was explained by differences in terms of learning process (Millot et al., 2008; Benhaïm et al., 2011). Overall, NT adapted to the self-feeding system without wasting feed as already observed in previous study (Fortes-Silva et al., 2010). Our study is the first showing the same results on BCT.

BCT showed strong diurnal feeding rhythms with high activity especially during the four hours following the onset of light and before light extinction. Some nocturnal feeding activity was also observed. The situation was much more variable in NT i.e. in one tank, a diurnal pattern was observed as already described by Toguyeni et al (1997) while in the other tank both diurnal and nocturnal patterns were observed. Forte-Silva et al (2010) observed a strict nocturnal feeding in NT. Our study suggests a flexible circadian feeding rhythm in NT that could be driven by food competition between males with subordinate males feeding at night to compensate for low diurnal food intake (Toguyeni et al., 1997).

Interestingly, the social structure based on the triggering activity was similar in both species and similar to that already observed in numerous studies on European sea bass (Millot et al., 2008; Millot and Bégout, 2009; Benhaïm et al., 2012) and European cod (Millot et al., 2014) self-feeding behavior, with three well represented categories : in a group of 20 individuals, only a few (1-3) were responsible for the majority of the food demand (high triggering fish) while 
the rest of the population could be divided into two groups, with low triggering fish that seldom actuated the trigger (about $15 \%$ of the population) and zero triggering fish that almost never actuate the device (about $75 \%$ of the population).

There were no growth differences between the triggering categories as earlier found in European sea bass (Benhaïm et al., 2011; Benhaïm et al., 2012; Ferrari et al., 2014). While there is no clear evidence of a link between sex and food demand in European sea bass, there seemed to be more females than males of the high-triggering fish in both tilapia species. This could be due to higher energy requirements for reproduction in females. Still, high-triggering fish were not exclusively females and the sex ratio was not balanced within tanks (about $60 \%$ females). The triggering activity could also be linked to behavioral traits such as boldness as discussed below.

\section{Open field test}

The behavior of the two species differed markedly in the open field test. Most NT individuals stayed in the shelter during the test while most BCT individuals left. In addition, the few NT individuals that left the shelter spent most of the time close to the walls of the arena or in the zone located near the shelter but almost never went to the center which is considered as a risky area (Maximino, 2010; Dahlbom, 2011). Overall, this suggests that NT is shyer than BCT but also that the open field test that involves handling and isolating the individuals is stressful for all of them regardless of their boldness level. Previous studies on Zebrafish, Danio rerio (Blaser and Vira, 2014) and European sea bass (Benhaïm et al., 2013a; Benhaïm et al., 2013b; Benhaïm et al., 2013c) showed that individuals that moved out of the shelter preferred to swim in the border zone but only a small proportion of them stayed in the shelter during all the experiment. NT is known to use structures as sheltering objects and refuges (Delicio, 2006b). In the wild, this species builds nests on gravel during reproduction (Gonçalves and Hoshino, 1990a; Barreto et al., 2003b; Volpato et al., 2004) and may use shelters as territories to hide from predators (Kolding, 1993). As a consequence, the open field test with a shelter seems to be not well adapted to characterize boldness among NT populations and has to the best of our knowledge never been tested before. Other tests such as feed intake recovery correlated with the rate of ventilation (Barreto and Volpato, 2011), or with restraining and novel object test (Martins et al., 2011c), thermal preference correlated with restraining, ventilation frequency, feed intake 
recovery and novel object test (Cerqueira et al., 2016) seem better adapted to discriminate coping styles in NT.

In contrast, the open field test was relevant to assess boldness in BCT. The proportion of time spent in the shelter that should provide a relevant indication of boldness varied substantially between individuals in accordance with previous studies (Budaev, 1999b; Fraser, 2001; Biro and Stamps, 2008; Eriksson, 2010; Benhaïm et al., 2016). Fish spent about 58\% of the time in the shelter and when they left, they spent equal time in the center, near the wall of the area and in the zone near the shelter. These results are similar to what is observed in European sea bass under similar conditions (Benhaïm et al., 2016), although BCT spent more time in the center indicating a slightly bolder behaviour.

The PCA approach allowed us to identify a clear Shelter/Latency to move out of the shelterBorder axis which can be used as a proxy for evaluating the shy-bold continuum in BCT as already shown in previous studies on European sea bass (Ferrari et al., 2014; Benhaïm et al., 2016). Linking the results of the self-feeding experiment and open field tests, we found a strong positive correlation between the triggering activity and shyness as recently shown in European sea bass under similar conditions (Ferrari et al 2014). However, taking BCT sex into account, this correlation was found to be significant in females only. Females that spent more time inside than outside the shelter and which latency to emerge from shelter was longer (i.e. shy individual) were characterized by higher triggering activity during the self-feeding experiment (high-triggering fish).

The triggering activity of BCT females may be linked to the individual innovative ability that in turn could be linked to personality traits. In our experiment, low triggering females (bolder individuals) could have priority access to food resource under the food dispenser whereas high triggering fish (shyer individuals) need to actuate the trigger until they can eat at will. A higher innovative ability in poor competitors (shy fish) has earlier been demonstrated (Cole and Quinn, 2012). Furthermore, as already suggested in studies on European sea bass (Di-Poï et al., 2008; Ferrari et al., 2014), the observed social pattern could be based on the producer-scrounger model firstly described by Barnard \& Sibly (1981). High triggering fish may play the role of the producers that feed the entire group, whereas other fish may play the role of scroungers, individuals that parasitically exploit the food made available by the producers. 


\section{Conclusions}

This study confirms the ability of NT to use self-feeder devices and provides the first insight into the same ability in BCT and further demonstrates links between the self-feeding activity and personality traits. Further research is needed to better assess growth performances in both species under self-feeding conditions increasing the number of replicates and comparing the fish at the same age. We focused on the social structure based on the triggering activity and its link with personality traits. Surprisingly social structures were similar in the two studied species and also similar to that observed in European sea bass or European cod under similar conditions. These species are characterized by very different behaviours in the wild but all of them are gregarious which can explain the similar social pattern observed. It would be interesting to assess NT personality traits using a relevant test and to verify whether it is correlated, similarly to BCT, to triggering activity under self-feeding conditions. Next step of this work will be to produce hybrid tilapia (NT females and BCT males and conversely) and to study their feeding behaviour, associated personality traits and further characterize social interactions such as aggression levels.

\section{Acknowledgments}

This experiment was made possible through funding provided by the Conseil Régional de Basse-Normandie and the Syndicat Mixte du Cotentin. The authors benefited greatly from the technical assistance of Didier Leguay.

All procedures performed followed the European Directive 2010/63 UE and this study was conducted under the approval of the French Ministère de l'Education, de l'Enseignement Supérieur et de la Recherche with project authorization number APAFIS\#263.

\section{References}

Alanärä, A., 1992. The effect of time-restricted demand feeding on feeding activity growth and feed conversion in rainbow trout (Oncorhynchus mykiss). Aquaculture 108, 357-368.

Alanärä, A., 1996. The use of self-feeders in rainbow trout (Oncorhynchus mykiss) production. Aquaculture 145, 1-20.

Amon, Y., Yao, K., Atse, B., Ouattara, M., 2013. Survie et croissance des juvéniles hybrides issus du croisement intergénérique Oreochromis niloticus (Linnaeus, 1758) et Sarotherodon Melanotheron (Rüppel, 1852) en milieu lagunaire. Int. J. Biol. Chem. Sci. 7, 1069-1077.

Barnard, C.J., Sibly, R.M., 1981. Producers and scroungers: a general model and its application to captive flocks of house sparrows. Anim. Behav. 29, 543-550. 
Barreto, R.E., Luchiari, A.C., Marcondes, A.L., 2003. Ventilatory frequency indicates visual recognition of an allopatric predator in naive Nile tilapia. Behav. Process. 60, 235-239.

Barreto, R.E., Moreira, P.S.A., Carvalho, R.F., 2003b. Sex-specific compensatory growth in food deprived Nile tilapia. Braz. J. Med. Biol. Res. 36, 477-483.

Barreto, R.E., Volpato, G.L., 2004. Caution for using ventilatory frequency as an indicator of stress in fish. Behav. Process. 66, 43-51.

Barreto, R.E., Volpato, G.L., 2011. Ventilation rates indicate stress-coping styles in Nile tilapia. Journal of Biosciences 36, 851-855.

Benhaïm, D., Bégout, M.-L., Chatain, B., 2013a. Unfamiliar congener used as a visual attractor in wild caught and domesticated sea bass (Dicentrarchus labrax) placed in a T-maze. Journal of Aquaculture Research Development 4, 169-175.

Benhaïm, D., Bégout, M.-L., Lucas, G., Chatain, B., 2013b. First insight into exploration and cognition in wild caught and domesticated sea bass (Dicentrarchus labrax) in a maze. PLoS ONE 8(6), e65872.

Benhaïm, D., Bégout, M.-L., Péan, S., Brisset, B., Leguay, D., Chatain, B., 2012. Effect of fasting on self-feeding activity in juvenile sea bass (Dicentrarchus labrax). Appl. Anim. Behav. 136, 63-73.

Benhaïm, D., Bégout, M.-L., Péan, S., Manca, M., Prunet, P., Chatain, B., 2013c. Impact of a plant-based diet on behavioural and physiological traits in sea bass (Dicentrarchus labrax). Aquat. Living Resour. 26, 121-131.

Benhaïm, D., Ferrari, S., Chatain, B., Bégout, M.-L., 2016. The shy prefer familiar congeners. Behav. Process. 126, 113-120.

Benhaïm, D., Péan, S., Bégout, M.-L., Brisset, B., Leguay, D., Chatain, B., 2011. Effect of size grading on sea bass (Dicentrarchus labrax) juvenile self-feeding behaviour, social structure and culture performance. Aquat. Living Resour. 24, 391-402.

Biro, P.A., Stamps, J.A., 2008. Are animal personality traits linked to life-history productivity? Trends Ecol. Evol. 23, 361-368.

Blaser, R.E., Vira, D.G., 2014. Experiments on learning in zebrafish (Danio rerio): A promising model of neurocognitive function. Neurosci. Biobehav. Rev. 42, 224-231.

Bolhuis, J.E., Schouten, W.G.P., Leeuw, J.A.d., Schrama, J.W., Wiegant, V.M., 2004. Individual coping characteristics, rearing conditions and behavioural flexibility in pigs. Behav. Brain Res. 152, 351-360.

Boujard, T., Jourdan, M., Kentouri, M., Divanach, P., 1996. Diel feeding activity and the effect of time-restricted self-feeding on growth and feed conversion in European sea bass. Aquaculture 139, 117-127.

Boujard, T., Le Gouvello, R., 1997. Voluntary feed intake and discrimination of diets containing a novel fluoroquinolone in self-feeding rainbow trout. Aquat. Living Resour. $10,343-350$.

Boujard, T., Leatherland, J.F., 1992. Demand-feeding behavior and diel pattern of feeding activity in Oncorhynchus mykiss held under different photoperiod regimes. J. Fish Biol. 40, 535-544.

Brännäs, E., Alanärä, A., 1993. Monitoring the feeding activity of individual fish with a demand feeding system. J. Fish Biol. 42, 209-215.

Budaev, S.V., Zworykin, D.D., Mochek, A.D.,, 1999a. Consistency of individual differences in behaviour of the lion-headed cichlid, Steatocranus casuarius. Behav. Process. 48, 4955.

Budaev, S.V., Zworykin, D.D., Mochek, A.D.,, 1999b. Individual differences in parental care and behaviour profile in the convict cichlid: a correlation study. Anim. Behav. 58, 195202. 
Cerqueira, M., Rey, S., Silva, T., Featherstone, Z., Crumlish, M., Mackenzie, S., 2016. Thermal preference predicts animal personality in Nile tilapia Oreochromis niloticus. J. Anim. Ecol. 85, 1389-1400.

Cole, E.F., Quinn, J.L., 2012. Personality and problem-solving performance explain competitive ability in the wild. Proceedings of the Royal Society B: Biological Sciences 279, 1168-1175.

Covès, D., Beauchaud, M., Attia, J., Dutto, G., Bouchut, C., Bégout, M.L., 2006. Long-term monitoring of individual fish triggering activity on a self-feeding system: An example using European sea bass (Dicentrarchus labrax). Aquaculture 253, 385-392.

Dagnélie, P., 1975. Théorie et méthodes statistiques. Applications agronomiques. Vol. II. Les méthodes de l'inférence statistique. Les Presses agronomiques, Gembloux, 463p.

Dahlbom, S.J., Lagman, D., Lundstedt-Enkel, K., Sundström, L.F., Winberg, S., 2011. Boldness predicts social status in zebrafish (Danio rerio). PLoS ONE 6, e23565.

Delicio, H.C., Barreto, R.E., Normades, E.B., Luchiari, A.C., Marcondes, A.L., 2006b. A place preference test in the fish Nile tilapia. J. Exp. Anim. Sci. 43, 141-148.

Delicio, H.C., Vicentini-Paulino, M.L.M., 1993. 2-deoxyglucose-induced food-intake by Nile tilapia, Oreochromis niloticus (L.). Braz. J. Med. Biol. Res. 26, 327-331.

Di-Poï, C., Attia, J., Bouchut, C., Dutto, G., Covès, D., Beauchaud, M., 2007. Behavioral and neurophysiological responses of European sea bass groups reared under food constraint. Physiol. Behav. 90, 559-566.

Di-Poï, C., Beauchaud, M., Bouchut, C., Dutto, G., Covès, D., Attia, J., 2008. Effects of high food demand fish removal in groups of juvenile sea bass (Dicentrarchus labrax). Can. J. Zool. 86, 1015-1023.

Eriksson, C.A., Booth, D.J., Biro, P.A., 2010. Personality in two species of temperate damselfish. Mar. Ecol. Prog. Ser. 420, 273-276.

Ferrari, S., Benhaïm, D., Colchen, T., Chatain, B., Bégout, M.-L., 2014. First links between self-feeding behaviour and personality traits in European seabass, Dicentrarchus labrax. Appl. Anim. Behav. 161, 131-141.

Fortes-Silva, R., Martinez, F.J., Villarroel, M., Sanchez-Vazquez, F.J., 2010. Daily rhythms of locomotor activity, feeding behavior and dietary selection in Nile tilapia (Oreochromis niloticus). Comparative Biochemistry and Physiology Part A: Molecular \& Integrative Physiology 156, 445-450.

Fortes-Silva, R., Sanchez-Vazquez, F.J., 2012. Use of self-feeders to evaluate macronutrient self-selection and energy intake regulation in Nile tilapia. Aquaculture 326-329, 168172.

Fraser, D., Gilliam, J., JDaley, M., NLe, A., Skalski, G., 2001. Explaining leptokurtic movement distributions: intrapopulation variation in boldness and exploration. Am. Naturalist 158, 124-135.

Gonçalves, E., Hoshino, K., 1990a. Behavioral lateralization in the freshwater fish Oreochromis nitolicus. Abstract translated from the Annals of the 5th Annual Meeting of the Federation of Brazilian Societies for Experimental Biology (FESBE). Caxambu, M.G., 25.

Hoare, W.S., Randall, D.J., 1979. Fish Physiology, Volume 8, Bioenergetics \& growth, Academic Press, New York, 703-704.

Hopkins, K., Ridha, M., Leclercq, D., Al-Ameeri, A.A., Al-Ahmad, T., 1989. Screening tilapias for sea water culture in Kuweit. Aquac. Fish. Manag. 20, 389- 397.

Ide, L.M., Hoffmann, A., 2002. Stressful and behavioural conditions that affect reversible cardiac arrest in the Nile tilapia, Oreochromis niloticus (Teleostei). Physiol. Behav. 75, 119-126. 
Kolding, J., 1993. Population-dynamics and life-history styles of Nile tilapia, Oreochromis niloticus, in Ferguson Gulf, Lake Turkana, Kenya. Env. Biol Fish. 37, 25-46.

Koolhaas, J.M., Korte, S.M., De Boer, S.F., Van Der Vegt, B.J., Van Reenen, C.G., Hopster, H., De Jong, I.C., Ruis, M.A.W., Blokhuis, H.J., 1999. Coping styles in animals: current status in behavior and stress-physiology. Neurosci. Biobehav. Rev. 23, 925-935.

MacKenzie, S., Ribas, L., Pilarczyk, M., Capdevila, D.M., Kadri, S., Huntingford, F.A., 2009. Screening for coping style increases the power of gene expression studies. PLoS ONE 4, e5314.

Martins, C.I.M., Castanheira, M.F., Engrola, S., Costas, B., Conceicao, L.E.C., 2011 a. Individual differences in metabolism predict coping styles in fish. Appl. Anim. Behav. $130,135-143$.

Martins, C.I.M., Conceição, L.E.C., Schrama, J.W., 2011b. Consistency of individual variation in feeding behaviour and its relationship with performance traits in Nile tilapia Oreochromis niloticus. Appl. Anim. Behav. 133, 109-116.

Martins, C.I.M., Conceição, L.E.C., Schrama, J.W., 2011c. Feeding behavior and stress response explain individual differences in feed efficiency in juveniles of Nile tilapia Oreochromis niloticus. Aquaculture 312, 192-197.

Maximino, C., de Brito, T.M., Dias, C.A.G.D., Gouveia, A., Morato, S., 2010. Scototaxis as anxiety-like behavior in fish. Nat. Protoc. 5, 209-216.

McCarthy, I.D., Carter, C.G., Houlihan, D.F., 1992. The effect of feeding hierarchy on individual variability in daily feeding of rainbow trout, Oncorhynchus mykiss (Walbaum). J. Fish Biol. 41, 257-263.

Millot, S., Bégout, M.-L., 2009. Individual fish rhythm directs group feeding: a case study with sea bass juveniles (Dicentrarchus labrax) under self-demand feeding conditions. Aquat. Living Resour. 22, 363-370.

Millot, S., Bégout, M.-L., Person-Le Ruyet, J., Breuil, G., Di-Poï, C., Fievet, J., Pineau, P., Roué, M., Sévère, A., 2008. Feed demand behavior in sea bass juveniles: effects on individual specific growth rate variation and health (inter-individual and intergroup variation). Aquaculture 274, 87-95.

Millot, S., Nilsson, J., Fosseidengen, J.E., Bégout, M.-L., Fernö, A., Braithwaite, V., 2014. Innovative behaviour in fish: Atlantic cod can learn to use an external tag to manipulate a self-feeder. Anim. Cogn. 17, 779-785.

Moreira, P.S.A., Volpato, G.L., 2004. Conditioning of stress in Nile tilapia. J. Fish Biol. 64, 961-969.

Ng, W.K., Wang, Y., 2011. Inclusion of crude palm oil in the broodstock diets of female Nile tilapia, Oreochromis niloticus, resulted in enhanced reproductive performance compared to broodfish fed diets with added fish oil or linseed oil. Aquaculture 314, 122 131.

Øverli, Ø., Sørensen, C., Nilsson, G.E., 2006. Behavioral indicators of stress-coping style in rainbow trout: Do males and females react differently to novelty? Physiol. Behav. 87, 506-512.

Paspatis, M., Maragoudaki, D., Kentouri, M., 2002. Feed discrimination and selection in selffed European sea bass Dicentrarchus labrax . Aquac. Res. 33, 509-514.

Rubio, V.C., Vivas, M., Sanchez-Mut, A., Sanchez-Vazquez, F.J., Coves, D., Dutto, G., Madrid, J.A., 2004. Self-feeding of European sea bass (Dicentrarchus labrax, L.) under laboratory and farming conditions using a string sensor. Aquaculture 233, 393-403.

Sih, A., Bell, A., Chadwick Johnson, J., 2004. Behavioral syndromes: an ecological and evolutionary overview. Trends Ecol. Evol. 19, 372-378.

Stickney, R.R., 1986. Tilapia resistance of saline waters: a review. Prog. Fish-Cult. 48, 161 167. 
Suresh, A.V., Lin, C.K., 1992. Tilapia culture in saline waters : a review. Aquaculture 106, 201 226.

Talbot, C., 1993. Some aspects of the biology of feeding and growth in fish. Proc. Nut. Soc. 52, 403-416.

Teoh, G.T., Turchini, G.M., Ng, W.K., 2011. Genetically improved farmed Nile tilapia and red hybrid tilapia showed differences in fatty acid metabolism when fed diets with added fish oil or a vegetable oil blend. Aquaculture 312, 126-136.

Thorpe, J.E., Cho, C.Y., 1995. Minimising waste through bioenergetically and behaviourally based feeding strategies. Water Sci.Technol. 31, 29-40.

Toguyeni, A., Fauconneau, B., Boujard, T., Fostier, A., Kuhn, E.R., Mol, K.O., Baroiller, J.F., 1997. Feeding Behaviour and Food Utilisation in Tilapia, Oreochromis niloticus: Effect of Sex Ratio and Relationship with the Endocrine Status. Physiol. Behav. 62, 273-279.

Trewavas, E., 1983. Tilapiine fishes of the genera Sarotherodon, Oreochromis and Danakilia. Br. Mus. (Nat. Hist.), London, 583 pp.

Trung, D.V., Diu, N.T., Hao, N.T., Glencross, B., 2011. Development of a nutritional model to define the energy and protein requirements of tilapia, Oreochromis niloticus. Aquaculture 320, 69-75.

Verbeek, M.E.M., Drent, P.J., Wiepkema, P.R., 1994. Consistent individual differences in early exploratory behaviour of male great tits. Anim. Behav. 48, 1113-1121.

Volkoff, H., Peter, R.E., 2006. Feeding Behavior of Fish and Its Control. Zebrafish 3, 131-140.

Volpato, G.L., Barreto, R.E., 2001. Environmental blue light prevents stress in the fish Nile tilapia. Braz. J. Med. Biol. Res. 34, 1041-1045.

Volpato, G.L., Duarte, C.R.A., Luchiari, A.C., 2004. Environmental color affect Nile tilapia reproduction. Braz. J. Med. Biol. Res. 37, 479-483.

Whitfield, A.K., Blaber, S.J.M., 1979. The distribution of the freshwater cichlid Sarotherodon mossambicus in estuarine systems. Environ. Biol. Fishes 4, 77-81.

Wilson, D., Clark, A., Coleman, K. \& Dearstyne, T., 1994. Shyness and boldness in humans and other animals. Trends Ecol. Evol. 9, 442-446.

Yoshida, M., Nagamine, M., Uematsu, K., 2005. Comparison of behavioral responses to a novel environment between three teleosts, bluegill Lepomis macrochirus, crucian carp Carassius langsdorfii, and goldfish Carassius auratus. Fisheries Science 71, 314-319.

Zar, J.H., 1984. Biostatistical analysis, 2nd edn. Prentice Hall, Englewood Cliffs. 


\section{Figure legends}

Fig. 1. Scheme and dimensions of the open field apparatus

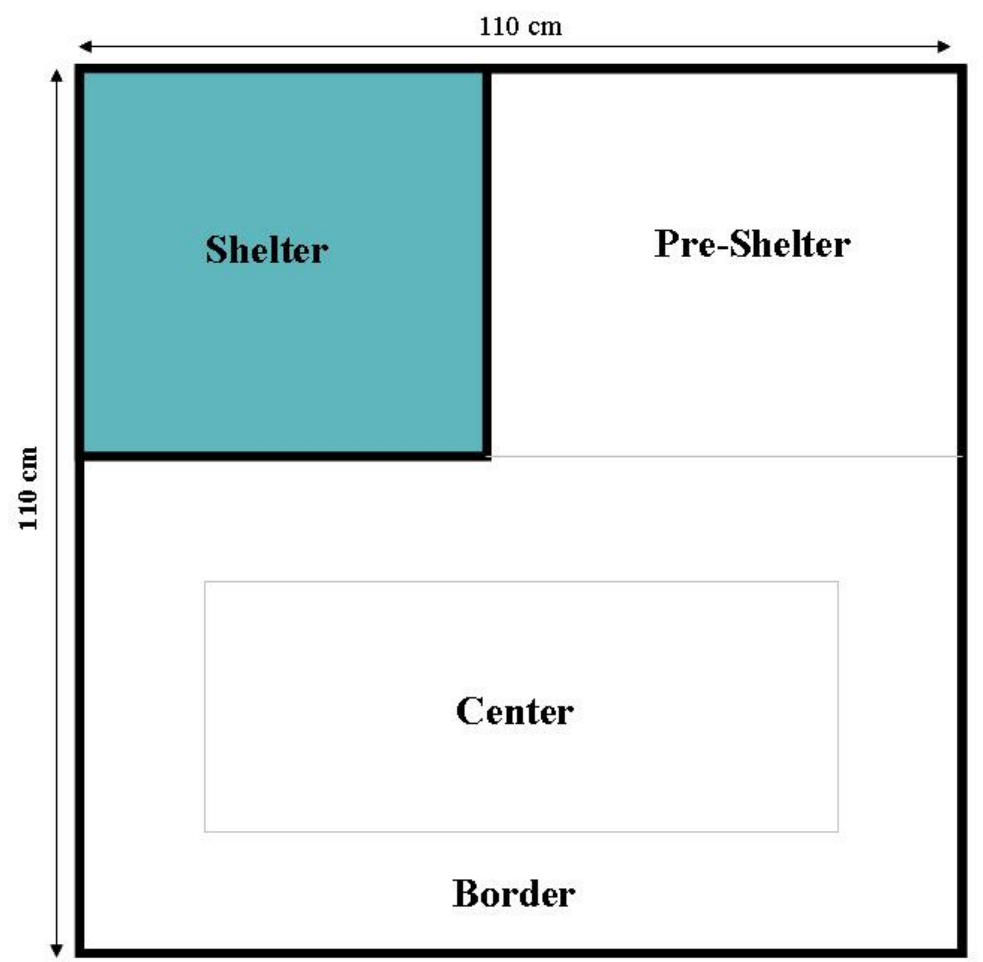


Fig. 2. Growth performances (mean \pm standard deviation) of Nile tilapia and Black-chinned tilapia under self-feeding conditions.
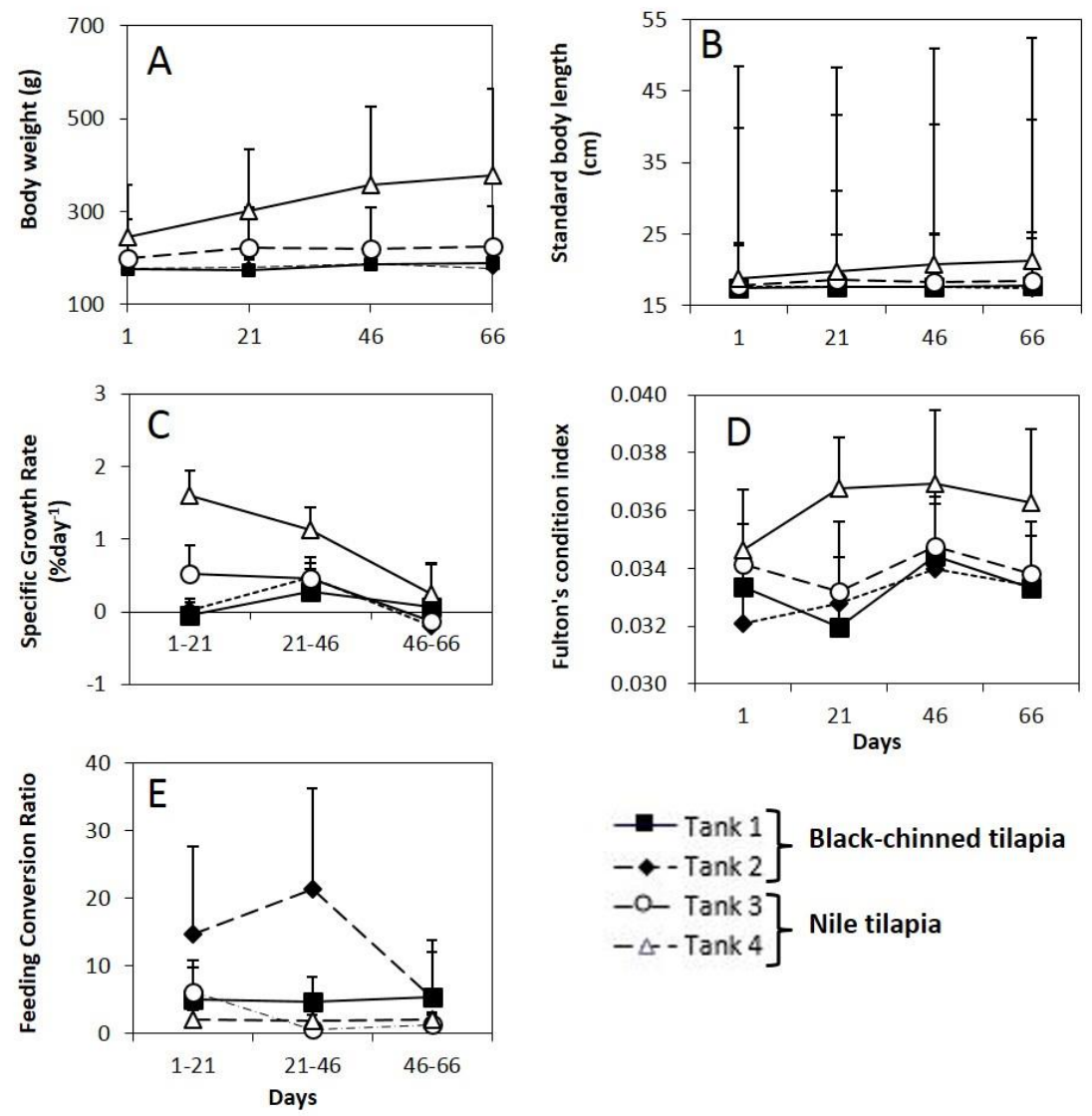

Fig. 3. Feeding rhythm (Mean \pm standard deviation). $\mathrm{T} 1$ and $\mathrm{T} 2$ are Black-chinned tilapia, T3 and T4 are Nile tilapia. The black mark on the X-axis represents the night period.
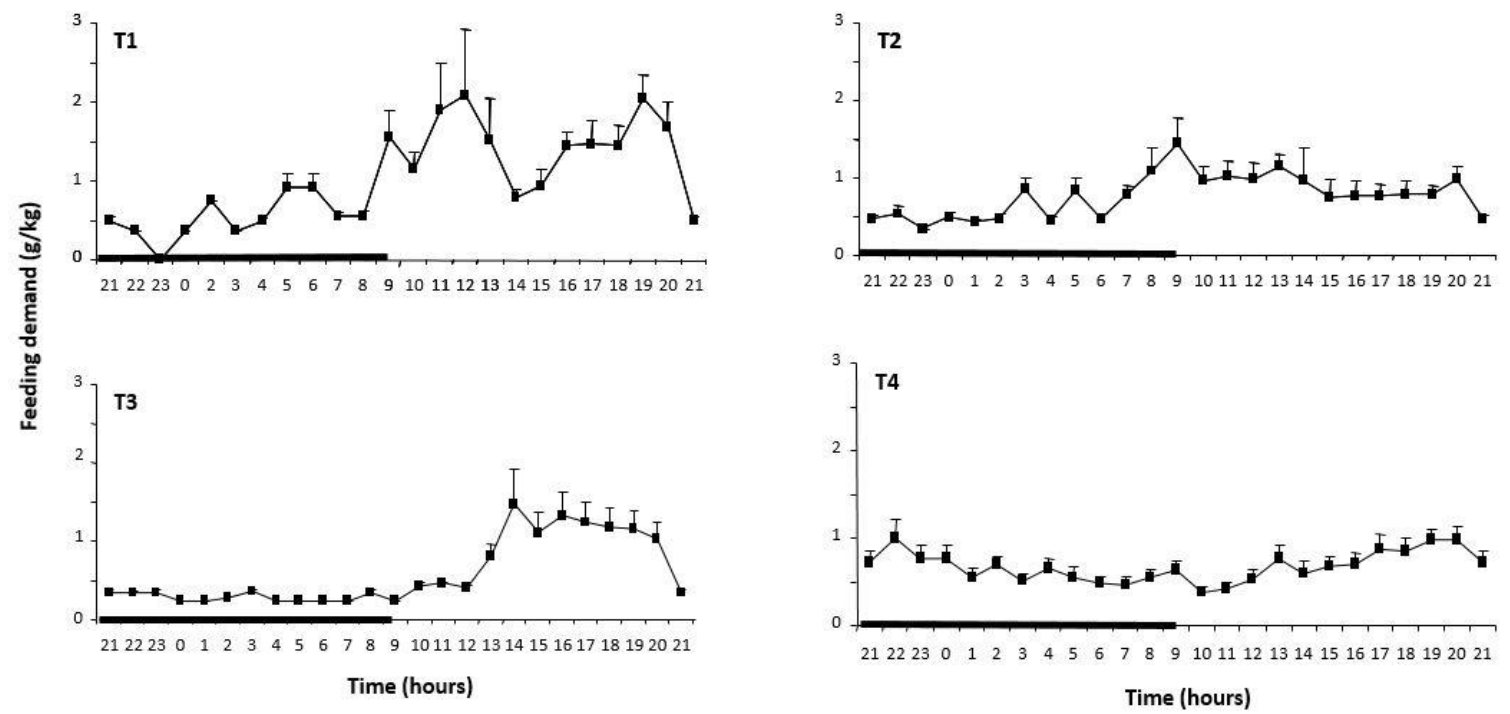
Fig. 4. Social structure measured by the percentage of triggering acts per individual in tanks 1 , 2, 3 and 4 (T1 to T4). BCT : Black-chinned tilapia, NT : Nile Tilapia.

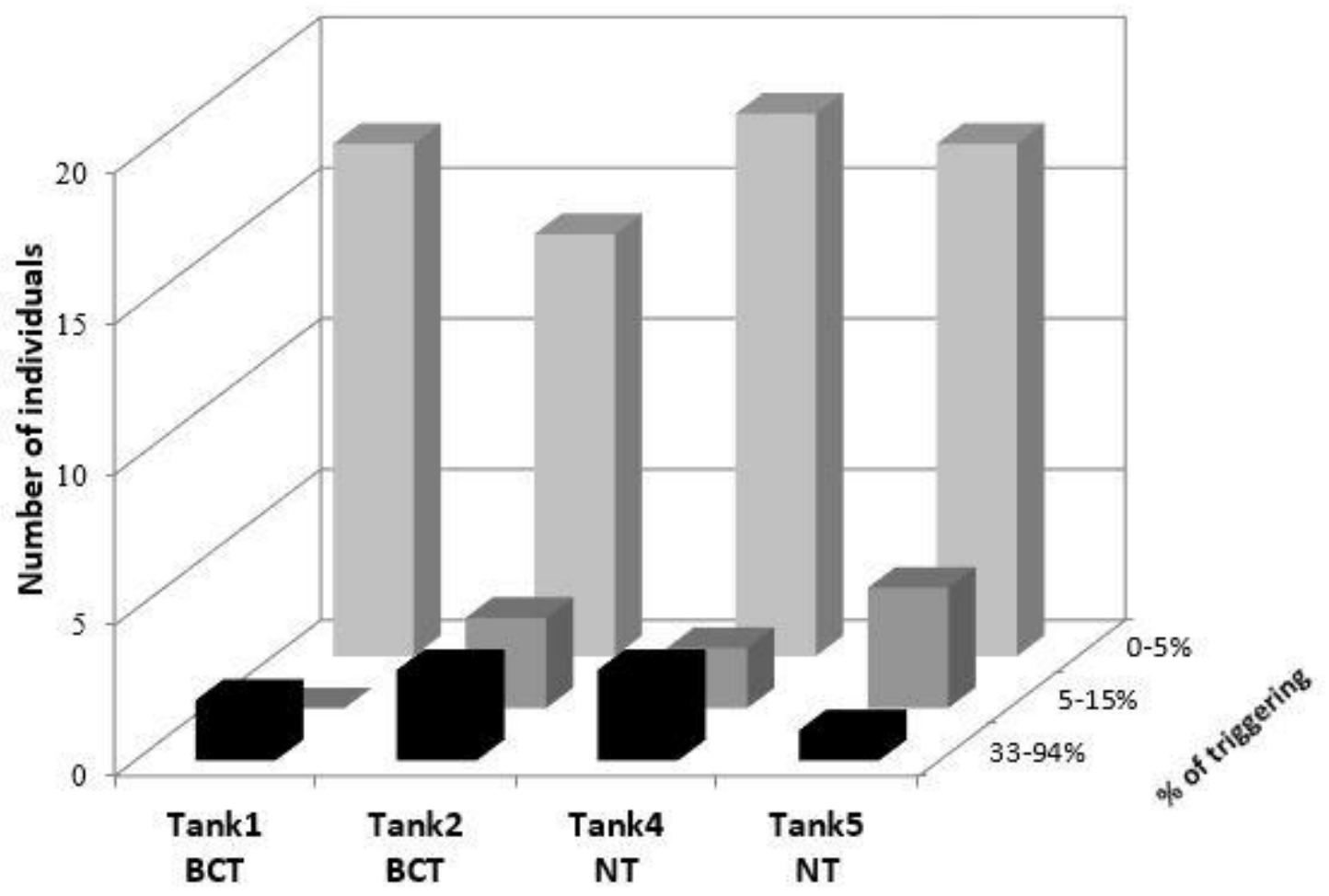


Fig. 5. Proportion of time spent (mean \pm standard deviation in $\%$ ) by Nile Tilapia (black bar) and Black-chinned tilapia (white bar) in each zone of the open field. Significant differences between species $(\mathrm{P}<0.001)$ are shown by an asterisk over the bars.

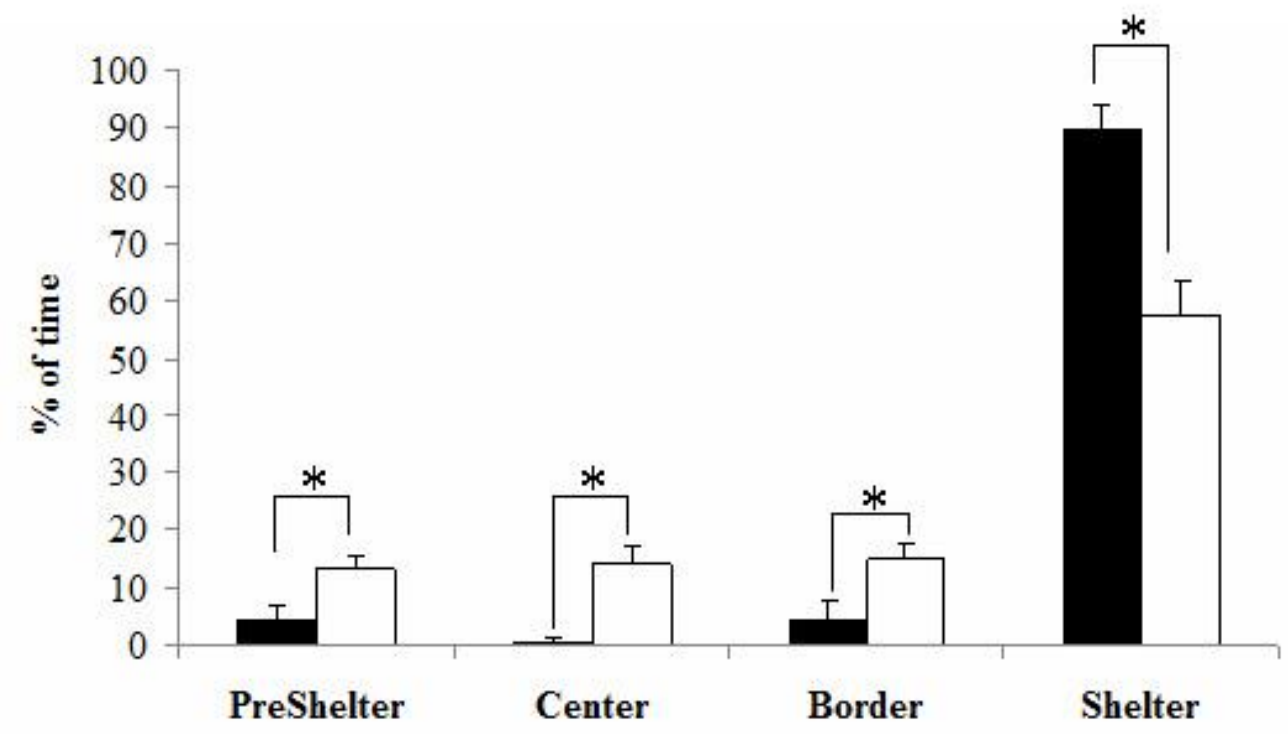


Fig. 6. Spearman's correlation between the total feed-demand activity in Black-chinned tilapia and the first principal component scores using Principal Components Analysis (PC1) in the open field test (OFT) for femalesr $r_{\mathrm{s}}=0.49, \mathrm{~N}=21, \mathrm{p}=0.02$, Equation for the best linear fit (continuous line) is: $\mathrm{y}=27.923 \mathrm{x}+61.032 .4$ and males, $\mathrm{r}_{\mathrm{s}}=0.24, \mathrm{~N}=16, \mathrm{p}=0.36$, Equation for the best linear fit (dotted line) is: $\mathrm{y}=4.3473 \mathrm{x}+17.144$.

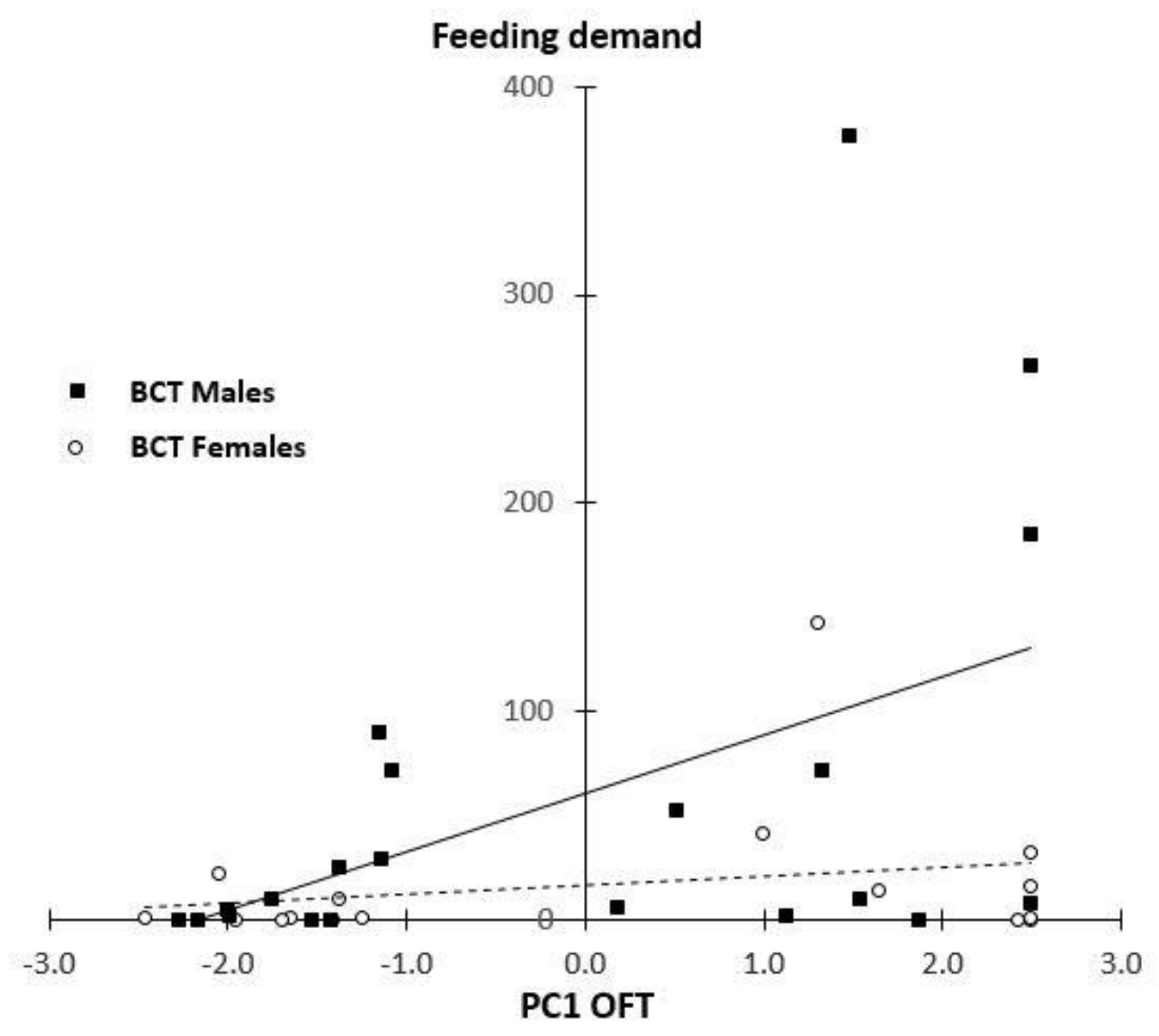

